\title{
Revisão de literatura sobre psicologia escolar na educação profissional, científica e tecnológica
}

\author{
Andreia Piana Titon', https://orcid.org/0000-0001-8114-1478 \\ Andrea Vieira Zanella², https://orcid.org/0000-0001-8949-0605
}

\begin{abstract}
Resumo
Considerando as dificuldades que o psicólogo escolar vem, historicamente, enfrentando para legitimar seu espaço de trabalho como membro das equipes técnicas de escolas públicas e o aumento significativo de psicólogos/as na rede de educação profissional e tecnológica nos últimos anos, esta pesquisa objetiva problematizar o que tem sido produzido sobre a psicologia escolar nesse contexto. Foi realizado levantamento em bases de dados no primeiro semestre de 2017 e selecionadas 34 publicações. Identificamos que todas as publicações são recentes, publicadas a partir de 2009 e possuem concentração geográfica maior nas regiões Centro-Oeste, Nordeste e Sul. Predominam discussões sobre questões específicas da vida escolar dos discentes e sobre a identidade do psicólogo escolar. Constatamos a influência das críticas aos modelos tradicionais de intervenção da psicologia escolar nos trabalhos. Por outro lado, existe a necessidade de maior ênfase na problematização dos contextos institucionais, assim como das condições que produzem e perpetuam as demandas escolares.
\end{abstract}

Palavras-chave: Revisão de literatura; psicologia escolar; ensino profissionalizante.

\section{Review of literatura on school psychology in professional, scientific and technological education}

\begin{abstract}
Considering the difficulties that the school psychologist has historically faced in order to legitimize his workspace as a member of the technical teams of public schools and the significant increase of psychologists in the network of professional and technological education in the last years, this research aims to problematize the which has been produced on school psychology in this context. A survey was carried out in databases in the first half of 2017 and 34 publications were selected. We have identified that all publications are recent, published since 2009 and have a greater geographic concentration in the Midwest, Northeast and South regions. Discussions about specific issues of students' school life and about the identity of the school psychologist predominate. We note the influence of criticism on the traditional models of school psychology intervention in the works. On the other hand, there is a need for greater emphasis on the problematization of institutional contexts, as well as on the conditions that produce and perpetuate school demands.
\end{abstract}

Keywords: Literature review; school psychology; vocational education.

\section{Revisión de literatura sobre psicología escolar en la educación profesional, científica y tecnológica}

\begin{abstract}
Resumen
Considerando las dificultades que el psicólogo escolar viene históricamente enfrentando para legitimar su espacio de trabajo como miembro de los equipos técnicos de escuelas públicas y el aumento significativo de psicólogos/as en la red de educación profesional y tecnológica en los últimos años, en esta investigación se tiene por objetivo problematizar lo que ha sido producido sobre la psicología escolar en ese contexto. Se realizó recogida en bases de datos en el primer semestre de 2017 y seleccionadas 34 publicaciones. Identificamos que todas las publicaciones son recientes, publicadas a partir de 2009 y poseen concentración geográfica mayor en las regiones Centro-Oeste, Nordeste y Sur. Predominan discusiones sobre cuestiones específicas de la vida escolar de los discentes y sobre la identidad del psicólogo escolar. Constatamos la influencia de las críticas a los modelos tradicionales de intervención de la psicología escolar en los estudios. Por otro lado, existe la necesidad de más énfasis en la problematización de los contextos institucionales, así como de las condiciones que producen y perpetúan las demandas escolares. Palabras clave: Revisión de literatura; psicología escolar; educación vocacional.

1 Instituto Federal de Educação, Ciência e Tecnologia de Santa Catarina - Itajaí - Santa Catarina - Brasil; andreia.titon@ifsc.edu.br

2 Universidade Federal de Santa Catarina - Florianópolis - SC - Brasil; azanella@cfh.ufsc.br
\end{abstract}




\section{Introdução}

Com o intuito de contribuir para a qualificação técnica e política dos/as psicólogos/as que trabalham na área da educação, o Sistema Conselhos de Psicologia decidiu, em assembleia realizada em 2007, dedicar o ano de 2008 à Educação. Com isso foi criado um debate nacional que destacou a contribuição da psicologia na luta pela consolidação de uma educação para todos, respaldada em princípios de compromisso social, dos direitos humanos e do respeito às diferenças enquanto fundamento para uma efetiva inclusão social.

Guzzo e Mezzalira (2011, p. 13), com base na sistematização do que foi debatido neste ano de 2008, afirmam que "o psicólogo escolar ainda encontra dificuldades para legitimar seu espaço de trabalho como membro das equipes técnicas presentes nas escolas públicas em todo território brasileiro". Considerando esses dados e o aumento significativo de psicólogos/as na rede de educação profissional e tecnológica nos últimos anos, esta pesquisa objetiva problematizar o que tem sido produzido sobre a inserção desses profissionais nesse contexto, visando contribuir com o debate sobre a atuação do psicólogo escolar. Trata-se, pois, de uma revisão sistemática da produção acadêmica sobre o tema.

Conforme Feitosa e Marinho-Araujo (2016), os primeiros registros de inserção do/a psicólogo/a nas antigas Escolas Técnicas e Centros Federais de educação profissional ocorreram no final da década de 1980. Posteriormente, houve um incremento na inclusão desse/a profissional no âmbito da carreira na Rede Federal de ensino, especialmente a partir de 2005 com legislações que passaram a incluir o/a psicólogo/a no quadro de pessoal das novas Instituições Federais de Educação. De acordo com levantamento realizado pelas autoras, até o primeiro semestre de 2016 foram identificados/as 461 psicólogos/as escolares trabalhando em diferentes unidades dos Institutos Federais.

O aumento do número de psicólogos/as nesse campo de atuação está diretamente relacionado com a expansão da Rede Federal de Educação Profissional, Científica e Tecnológica. Em 2008, com a Lei 11.892, os Centros Federais de Educação Tecnológica (CEFETs) foram substituídos pelos Institutos Federais de Educação, Ciência e Tecnologia (IFETs). Desde 2003 essas instituições estavam em processo de expansão no país; no entanto, com essa nova legislação ocorreram mudanças tanto na quantidade de instituições que foram criadas quanto nas diretrizes para a Rede Federal de Educação Profissional, Científica e Tecnológica instituída a partir desse momento.

Conforme dados do Ministério da Educação (MEC), de 1909 a 2002 foram criadas 140 escolas técnicas. Entre 2003 e 2016, com o plano de expansão dessa rede, foram construídas 500 novas unidades, totalizando 644 campi em funcionamento, vinculados a 38 Institutos Federais presentes em todos os estados. Em Santa Catarina, por exemplo, são dois Institutos Federais: o Instituto Federal Catarinense (IFC), com 15 campi distribuídos em diferentes cidades e o Instituto Federal de Santa Catarina (IFSC), com 22 campi.
Atualmente são 38 Institutos Federais presentes em todos os estados, oferecendo cursos técnicos, superiores de tecnologia, licenciaturas e pós-graduações. A rede de educação profissional, científica e tecnológica também é formada por instituições que não aderiram aos Institutos Federais. São dois Cefets, 25 escolas técnicas vinculadas a Universidades, o Colégio Pedro II e uma Universidade Tecnológica (MEC, 2017).

Conhecer as práticas da psicologia escolar nessas instituições consiste, pois, em um meio de visibilizar esse campo de atuação da psicologia e contribuir com o debate sobre as possibilidades e desafios nas intervenções do psicólogo escolar.

\section{Método}

Esta pesquisa tem o objetivo de fazer uma revisão sistemática das produções acadêmicas relacionadas à inserção do psicólogo escolar na educação profissional, científica e tecnológica no contexto brasileiro. Justifica-se o recorte geográfico em razão das especificidades da educação profissional no Brasil, sendo foco de interesse a inserção recente de profissionais de psicologia nesses contextos.

No primeiro semestre de 2017 realizamos pesquisas em bases de dados (Portal de Periódicos da CAPES/MEC, Biblioteca Eletrônica do Scielo e Banco de Teses \& Dissertações da CAPES) procurando trabalhos que apresentassem discussões com interface entre a psicologia escolar e a educação profissional, científica e tecnológica. Foram utilizados os seguintes descritores: "psicologia escolar" AND: "ensino profissionalizante"; "educação profissional"; "Instituto Federal"; CEFET; "Escola Técnica". Durante a análise do material encontrado, foi realizada a leitura dos resumos e excluídas todas as publicações que não incluíam discussões sobre as possibilidades teórico-práticas de atuação do psicólogo escolar no contexto da educação profissional e tecnológica, como por exemplo, discussões sobre perspectivas de intervenção do/a psicólogo/a como docente.

Devido ao número restrito de publicações encontradas, não delimitamos um período para a busca. No Portal de Periódicos da CAPES/MEC encontramos o total de 52 trabalhos com os descritores citados. No entanto, após leitura dos resumos e trabalhos completos identificamos que apenas três artigos tratavam do tema desse trabalho (Macêdo \& Souza, 2009; Prediger \& Silva, 2014; Rocha \& Atem, 2010). Na Biblioteca Eletrônica do Scielo encontramos 12 artigos, mas apenas um tratava do tema dessa revisão de literatura, o mesmo encontrado nos Periódicos da CAPES. No Banco de Teses \& Dissertações da CAPES foram encontradas nove teses/dissertações, das quais foram selecionadas três dissertações (M. F. Costa, 2013; Moura, 2015; Prediger, 2010) e uma tese (Pandita-Pereira, 2016).

Com o intuito de ampliar os resultados encontrados, fizemos um levantamento de publicações no Google Acadêmico. Com os descritores "psicologia escolar" AND "educação profissional e tecnológica" encontramos 152 
resultados. A partir da leitura dos títulos, resumos e alguns trabalhos completos, selecionamos 16 novas publicações: seis capítulos de livros (Feitosa, 2016; Feitosa \& Marinho-Araujo, 2016a, 2016b; Petracco, 2010; D. M. Silva, Sarmento, Cunha, Santana Neto, \& Coutinho, 2013), cinco artigos (Andreis, Boaria, Andrade, Olea, \& Dias, 2014; Bisinoto \& Marinho-Araujo, 2015; Cristino, Fiorio, Oliveira, Felipe, \& Santos, 2016; Gomes, Padovani, Dazzani, \& Ristum, 2014; Scacchetti \& cols., 2015) três dissertações de mestrado (Bonfante, 2014; Gomes, 2014; Urt, 2015) e três teses de doutorado (Feitosa, 2017; Oliveira, 2011; Petracco, 2017).

Por fim, em outra busca, com os descritores "psicologia escolar" AND "Instituto Federal", encontramos 371 resultados. Após leitura dos títulos, resumos e de alguns textos completos, selecionamos oito novas publicações: cinco artigos (Bleicher \& Oliveira, 2016; Carlotto \& cols., 2015; Ferro \& Antunes, 2015; Morais, Benelli, \& Monteiro, 2013; Morais, 2010), três dissertações de mestrado (Bertollo-Nardi, 2014; M. O. Costa, 2016; Morais, 2011) e duas teses de doutorado (Schwede, 2016; R. M. Silva, 2015).

Considerando as produções selecionadas nas bases de dados, foram definidas como material para esta pesquisa 34 publicações: 13 artigos, nove dissertações de mestrado, seis capítulos de livros e seis teses de doutorado. A partir da leitura integral dessas publicações foi possível analisar informações como: ano de publicação, tipo de trabalho (artigo, tese/dissertação, capítulos de livros), filiação institucional, temáticas abordadas, público alvo das pesquisas, questionamentos e desafios da atuação no campo da educação profissional e tecnológica, demandas e espaços ocupados pelo psicólogo escolar e concepções e proposições para atuação do/a psicólogo/a na educação profissional e tecnológica.

\section{Resultados}

Das 34 produções analisadas, observamos que uma foi publicada em 2009, quatro em 2010, duas em 2011, três em 2013, seis em 2014, sete em 2015, nove em 2016 e duas em 2017. Podemos observar que todas as publicações encontradas sobre a psicologia escolar na educação profissional e tecnológica são recentes, publicadas a partir de 2009. Importante destacar o crescimento nestas publicações, o que está relacionado com a inserção dos profissionais da psicologia neste contexto, principalmente a partir da criação dos Institutos Federais em 2008.

Quanto às regiões geográficas onde esses trabalhos foram produzidos, observamos que existe uma maior concentração na Região Centro-Oeste do país (Brasília, Goiás e Mato Grosso do Sul), com 11 publicações; Nordeste (Bahia, Ceará, Pernambuco e Rio Grande do Norte), com 10 trabaIhos; e Sul (Santa Catarina, Rio Grande do Sul e Paraná) com oito publicações. No Centro-Oeste, destaca-se ainda o número de trabalhos vinculados a pesquisadores/as da Universidade de Brasília. Os demais estão distribuídos da seguinte forma: Sudeste (Espírito Santo e São Paulo), com três trabalhos; e Norte (Rondônia) com duas publicações.
Em relação às universidades onde foram realizadas as pesquisas de mestrado e de doutorado (nove dissertações e seis teses), identificamos que as dissertações estão vinculadas a diferentes universidades: UNIR (2 dissertações), UFRGS (1), UFES (1), UCB (1), UFG (1), UFBA (1), UFRJ (1) e UFMS (1). Quanto às teses de doutorado, duas são da UNB, duas da USP, uma da UFSCar e uma da PUCRS. Destacamos que com exceção de uma dissertação e uma tese, as demais estão vinculadas à Programas de Pós-Graduação na área da psicologia.

Identificamos ainda que oito dissertações e cinco teses foram realizadas por psicólogas/os que trabalham em Institutos Federais. Quanto aos artigos e capítulos de livros, identificamos nove trabalhos que possuem autoria de psicólogos/as que também trabalham em instituições da rede de educação profissional e tecnológica. Alguns destes artigos estão relacionados com publicações vinculadas às pesquisas apresentadas nas dissertações e teses encontradas.

Em relação às temáticas das publicações, observamos que 15 das 34 publicações analisadas possuem como temática principal a atuação do psicólogo escolar. Dessas, cinco enfatizam a atuação no ensino superior, no contexto da educação profissional e tecnológica. As demais possuem temáticas diversas: concepções sobre educação profissional, científica e tecnológica, inclusão escolar de aluno com surdez, processo de implantação da política de cotas raciais, relatos de intervenção de equipes de assistência estudantil e pesquisas com foco em questões específicas da vida escolar do discente (criatividade e bem estar, adaptação acadêmica, significados sobre o processo de escolarização, suporte parental e desempenho acadêmico, identidade psicossocial, adaptação social dos adolescentes em regime de internato, escolha profissional, estratégias de aprendizagem, relações entre a cultura institucional e os trotes). Observou-se que predominam publicações relacionadas a questões específicas da vida escolar dos discentes e a identidade do psicólogo escolar neste contexto.

Sobre o público alvo das pesquisas, identificamos um número significativo de publicações ao trabalho do psicólogo escolar (14 trabalhos) e pesquisas com foco nos jovens do Ensino Médio Integrado (13 trabalhos). As demais pesquisas apresentam públicos diversos: alunos do PROEJA, estudantes cotistas, estudantes em regime de internato, estudantes universitários, estudante com surdez, entre outros.

\section{Questionamentos e desafios da atuação no campo da educação profissional e tecnológica}

Um dos questionamentos presente nos trabalhos analisados refere-se ao papel da psicologia escolar no contexto da educação profissional e tecnológica, questão recorrente nas produções bibliográficas que tem como foco a atuação do psicólogo escolar. Nas publicações de profissionais que trabalham nesse contexto, a discussão sobre os limites e possibilidades da atuação também se faz presente (Bertollo-Nardi, 2014; M. O. Costa, 2016; 
Feitosa, 2017; Petracco, 2010; Prediger, 2010; Prediger \& Silva, 2014; Rocha \& Atem, 2010). Destacam-se, nessas produções, questões sobre quais práticas cabem nesse contexto, assim como sobre os desafios na construção de novas práticas profissionais que rompam com expectativas de intervenções pautadas em modelos psicologizantes e medicalizantes.

É possível identificar nos trabalhos analisados questionamentos e discussões relacionadas ao papel do psicólogo escolar que são recorrentes na literatura, como por exemplo, sobre as expectativas institucionais em relação à atuação do/a psicólogo/a voltada às queixas escolares. Por outro lado, observam-se questões que são específicas do contexto da educação profissional e tecnológica. Para ilustrar esse aspecto podemos citar o trabalho de Prediger (2010) e Prediger e Silva (2014).

Prediger (2010), em sua pesquisa de mestrado, buscou conhecer os diálogos que estavam ocorrendo entre os objetivos da educação profissional, científica e tecnológica com as práticas do psicólogo escolar. Para isso, utilizou como dispositivos de análise um questionário enviado por e-mail aos profissionais dos IFETs e a criação de um Fórum Virtual de discussão sobre as práticas da psicologia escolar. Prediger e Silva (2014) trazem reflexões sobre os desafios colocados para os/as psicólogos/as que ingressaram nos Institutos Federais. Esses estão relacionados com a necessidade, relatada pelos/as psicólogos/as participantes da pesquisa, de desenvolver novos modos de intervir na escola superando expectativas e demandas de intervenções voltadas para a adaptação e ajustamento dos estudantes quanto ao que é considerado como "normal" ou "adequado". Ao mesmo tempo, os Institutos Federais também estão enfrentando o desafio de construir suas práticas, pois apesar da educação profissional e tecnológica ser centenária no país, os Institutos possuem novas diretrizes para a educação profissional e tecnológica, assim como outra estrutura organizacional, voltada para diferentes modalidades, níveis de ensino e públicos atendidos.

Observamos ainda que entre os desafios da atuação nesse contexto está a formação do psicólogo escolar, o ingresso recente desse profissional nessas instituições e as próprias mudanças institucionais decorrentes da criação dos Institutos Federais. Na pesquisa realizada por Prediger e Silva (2014, p. 938), as autoras relatam que um dos principais efeitos da pesquisa-intervenção realizada foi "o rompimento com o lugar de solidão dos/as psicólogos/as e a criação de possibilidades de interlocução", pois a maioria dos participantes eram profissionais recém admitidos nos Institutos Federais.

Por outro lado, a formação desses profissionais também pode estar contribuindo para essas dificuldades, o que é relatado por Feitosa (2016). Conforme a autora, em pesquisa realizada com profissionais de um Instituto Federal da região centro-oeste, os relatos dos participantes apresentaram indicadores de que os enfoques organizacional e clínico foram mais evidenciados do que a psicologia escolar em suas formações. As lacunas na formação e as demandas no contexto educativo contribuíram para que esses profissionais procurassem cursos ou atualizações na interface entre psicologia e educação. Por outro lado, a autora (Feitosa, 2016, p. 39) observa que estes percursos de aperfeiçoamento ainda estão pautados "em concepções teóricas que direcionam a intervenção para possíveis queixas escolares e aspectos psicossociais dos estudantes no cotidiano escolar."

Outra questão presente na maioria dos trabalhos é referente às mudanças na política de educação profissional e tecnológica. Feitosa e Marinho-Araujo (2016b), por exemplo, discutem as mudanças ocorridas na educação profissional e tecnológica no Brasil nas últimas décadas e afirmam que é do interesse da psicologia escolar o

\begin{abstract}
caráter educativo inovador trazido pelo nível superior de ensino nos IFET's, por permitir diferentes escolhas dos estudantes nos percursos da formação, a inclusão de oportunidades na formação discente, a consolidação das mudanças no âmbito do ensino profissionalizante e o fortalecimento da comunidade acadêmica.(p. 15).
\end{abstract}

\section{Demandas e espaços ocupados pelo psicólogo escolar}

Nas publicações analisadas identificamos, assim como relatam Feitosa e Marinho-Araújo (2016c) e Feitosa (2017), que a inserção dos/as psicólogos/as nos Institutos Federais envolve um amplo conjunto de ações, relacionadas aos processos de ensino, aprendizagem e de assistência ao discente. No entanto, destacam que predominam intervenções com foco nos estudantes, o que também constatamos nos trabalhos analisados.

Observamos nos trabalhos encontrados, assim como é destacado por Feitosa $(2016,2017)$ e por Feitosa e Marinho-Araujo (2016a, 2016b; 2016c), que um dos principais eixos de atuação do psicólogo escolar nos Institutos Federais é na interface com a política de assistência estudantil.

Estas ações estão regulamentadas pelo Decreto 7.234/2010, que dispõe sobre o Programa Nacional de Assistência Estudantil - PNAES no âmbito das instituições federais de ensino superior, incluindo os IFETs. Esse programa visa ampliar as condições de permanência dos estudantes nestas instituições educacionais. Além disso, prevê que as ações de assistência estudantil sejam desenvolvidas nas seguintes áreas: moradia estudantil, alimentação, transporte, atenção à saúde, inclusão digital, cultura, esporte, creche, apoio pedagógico e acesso, participação e aprendizagem de estudantes com deficiência, transtornos globais do desenvolvimento, altas habilidades e superdotação.

Dos trabalhos analisados que possuem essa interface com a política de assistência estudantil, destacamos: relatos de experiência sobre atividades desenvolvidas por setores de assistência estudantil (Cristino \& cols., 2016; Ferro \& Antunes, 2015; D. M. Silva \& cols., 2013) uma pesquisa sobre a implantação da Lei de Cotas, problematizando os embates presentes nas ações afirmativas para estudantes oriundos de escolas públicas, pretos, pardos e indígenas (Moura, 
2015); uma pesquisa sobre a inclusão de estudantes com deficiência, a partir da discussão de um estudo de caso da trajetória escolar de uma pessoa surda (M. F. Costa, 2013); trabalhos sobre a identidade psicossocial de adolescentes que vivenciam o regime de internato durante sua formação (Morais \& cols., 2013; Morais, 2010, 2011); entre outros.

Moura (2015) destaca que o interesse por estudar as ações afirmativas surgiu no contexto em que trabalha, ao observar que a aprovação da Lei de Cotas (Lei n. 12.711, 2012) gerou discursos que a ela se contrapunham tanto no Instituto Federal em que estava inserida, quanto na sociedade como um todo. Ressalta a importância de estudar os impactos das ações afirmativas por compreender os fenômenos escolares nas suas inter-relações com as questões políticas, econômicas, sociais e culturais.

Petracco (2010) e Bertollo-Nardi (2014), por sua vez, apresentam e discutem o processo de implantação do Serviço de Psicologia nos campi onde ingressaram como psicólogas. Petracco (2010) relata os projetos que estavam em fase de implantação: formação de equipe multidisciplinar; levantamento do perfil das turmas de discentes; acompanhamento psicológico ao corpo docente em reuniões mensais; oficinas educativas para funcionários terceirizados; participação em atividades educativas em sala de aula; atendimento psicológico individual; participação em atividades educativas fora da sala de aula; e construção de projeto de atendimento educativo a crianças/adolescentes em situação de vulnerabilidade social.

Bertollo-Nardi (2014), em sua tese, analisa duas intervenções realizadas em suas práticas profissionais com estudantes dos cursos técnicos integrados ao ensino médio: As Rodas de Conversa e os Grupos de Orientação Profissional. Num primeiro momento da pesquisa, realizou um levantamento com os estudantes sobre suas demandas e representações de psicólogo/a, por meio de um questionário e de um grupo focal (Bertollo-Nardi, Avellar, Silva, Trindade, \& Menandro, 2014). Num segundo momento, realizou as Rodas de Conversa e os Grupos de Orientação Profissional, considerando as demandas levantadas junto com os jovens. No decorrer da tese, Bertollo-Nardi (2014) descreve e analisa o processo de construção destas intervenções no contexto em que está inserida.

A questão da possibilidade de intervenção do psicólogo escolar voltada para a orientação profissional com jovens dos Institutos Federais também é abordada por Rocha e Atem (2010). Os autores discutem algumas especificidades na intervenção do psicólogo escolar voltada para a orientação profissional com jovens que ingressam em cursos de educação profissional técnica de nível médio na forma integrada com o ensino médio. Os autores consideram que a escolha profissional destes estudantes é um dos novos desafios institucionais nos IFETs. Conforme os autores, a escolha profissional destes jovens é uma questão relevante por

... trazer à tona dilemas da opção por uma carreira profissional, as dúvidas relativas à inserção no mercado de trabalho e as consequências dos equívocos daí decorrentes
— evasão, repetência, queixas de inadaptação e sofrimentos psíquicos associados - para jovens com idades em que, tradicionalmente no Brasil, essa problemática não é colocada. (Rocha \& Atem, 2010, p. 68).

Apesar de observamos uma predominância de trabaIhos com foco nos estudantes, é possível observar também ações envolvendo outros atores do contexto institucional (Petracco, 2010, 2017; D. M. Silva \& cols., 2013; Urt, 2015). Urt (2005) e Petracco (2017), por exemplo, analisam as concepções e sentidos sobre a educação profissional, científica e tecnológica de professores e outros atores da comunidade escolar, evidenciando a necessidade de escutar e problematizar estas concepções.

\section{Concepções e proposições para atuação do psicólogo escolar}

Em relação aos referenciais teórico-metodológicos que fundamentam as publicações encontradas destacamos: Psicologia Histórico-Cultural (12 trabalhos), Psicanálise com interface com outras perspectivas teóricas (6), Análise Institucional (2), Psicologia Social (1), Psicologia Cultural do Desenvolvimento (1) e Teoria Crítica da Sociedade (2). Nos demais trabalhos não foi possível identificar o referencial teórico predominante.

Apesar da diversidade de referenciais teóricos, observamos na maioria dos trabalhos analisados a influência do percurso histórico de construção de perspectivas críticas de atuação em psicologia escolar. Além disso, destacamos em alguns trabalhos o questionamento sobre o papel que a escola assume na contemporaneidade e a necessidade de construção de novas práticas do/a psicólogo/a envolvendo todo o contexto institucional, o que implica as relações de ensino-aprendizagem, as relações com os diferentes atores institucionais e com a própria política educacional vigente.

Schwede (2016), em sua pesquisa de doutorado, busca compreender as concepções teórico-metodológicas que dão sustentação às práticas do psicólogo escolar após o período de crítica que ocorreu a partir da década de 1980. A partir de uma perspectiva crítica da psicologia escolar fundamentada na psicologia histórico-cultural, a autora analisa artigos científicos sobre a atuação do psicólogo escolar publicados no período entre 2000 e 2014 . A partir da análise dos artigos são apresentadas reflexões sobre as concepções teóricas que dão sustentação à atuação do psicólogo escolar, sobre as práticas dos/as psicólogos/as que atuam na educação e sobre os desafios encontrados pelos profissionais. A partir dessas reflexões, a autora (Schwede, 2016, p. 287) defende a tese de que

... a Psicologia Escolar e Educacional fundamentada na Psicologia Histórico-Cultural tem se consolidado como um movimento de cunho teórico-metodológico de resistência a concepções de Homem que se submetem à dominação econômica e social, pois a atuação de psicólogos escolares 
está passando por transformações em relação a práticas outrora consolidadas.

Feitosa (2016, 2017) e Feitosa \& Marinho-Araujo (2016a, 2016b, 2016c), por sua vez, apresentam a proposta de uma atuação institucional coletiva e preventiva do psicólogo escolar. Feitosa e Marinho-Araújo (2016c) afirmam que essa atuação deve desenvolver estratégias ampliadas envolvendo os programas educacionais, a gestão e a construção do perfil discente. Feitosa (2017), em sua tese de doutorado, defende esse modelo de intervenção para a construção de processos de mediação juntos aos atores educacionais com o intuito de contribuir com uma formação acadêmica articulada com a formação para o trabalho. Em sua pesquisa, a autora tem como foco as práticas dos psicólogos escolares no ensino superior nos Institutos Federais. Além disso, apresenta uma proposta de orientações técnicas para a intervenção dos/ as psicólogos/as neste contexto, a partir dos seguintes eixos: mapeamento de rotinas institucionais; acompanhamento das práticas institucionais e pedagógicas do curso; e apoio à trajetória acadêmica e profissional dos estudantes.

A possibilidade de intervenções voltadas para uma perspectiva mais coletiva e institucional se torna um desafio nas práticas profissionais em decorrência da complexidade e da diversidade de demandas no contexto da educação profissional e tecnológica e da própria formação dos/as psicólogos/as, que precisa abarcar tanto aspectos técnicos quanto políticos. Na pesquisa realizada por Feitosa (2016, p. 40) com psicólogos/as que trabalham em Institutos Federais, ela conclui que,

Por um lado, têm-se psicólogos escolares sensíveis a ressignificação do que se já foi concebido tradicionalmente por psicologia escolar; e de outro, os mesmos profissionais questionando a continuidade de ações práticas que, ainda, reverberam os indicadores de uma atuação de caráter psicoterapêutico e individualizante.

Em relação às concepções sobre psicologia escolar, os relatos "contemplaram aspectos que evidenciam que a psicologia escolar não pode ser concebida pela descontextualização e pela fragmentação do sujeito, pela naturalização dos processos de desenvolvimento humano e por práticas psicológicas individualizantes" (Feitosa, 2016, p. 39). A autora constata um movimento embrionário de ressignificação da identidade profissional nos campi onde esses psicólogos/as atuam, apesar das concepções de psicologia escolar ainda estarem permeadas pela expectativa de revisão da atuação profissional. Compreende a autora que essa transição pode ser favorável para a sistematização e implementação de uma intervenção institucional e crítica nesse contexto.

\section{Discussão}

A diversidade de temáticas nos trabalhos encontrados apresenta indicadores da complexidade das demandas escolares apresentadas aos psicólogos/as no cotidiano das instituições de educação profissional e tecnológica. Destacamos a importância de uma escuta dessas demandas a partir da compreensão do conjunto de relações institucionais, históricas, psicológicas, pedagógicas que constituem o cotidiano escolar (Zanella, 2003). Nesse sentido, é fundamental compreender também o contexto em que se insere a política de educação profissional, científica e tecnológica na contemporaneidade.

Os espaços de trabalho ocupados pelos/as psicólogos/as nesse contexto caracterizam-se por situações complexas e diversas decorrentes de uma política educacional em processo de reformulação e implementação, abarcando diferentes níveis, modalidades de ensino e público alvo. Além disso, destaca-se a interface desta política educacional com as ações afirmativas e com o Programa de Assistência Estudantil (PNAES), diretamente relacionados com a inserção dos/as psicólogos/as neste contexto. Importante destacar também as disputas de interesses e de posições ideológicas no interior da política de educação profissional e tecnológica, assim como das políticas educacionais numa perspectiva inclusiva.

Sobre a educação profissional e tecnológica no Brasil, Frigotto (2007) destaca que é importante compreender as relações entre trabalho, educação básica e formação profissional e tecnológica, nos diferentes contextos históricos. Segundo o autor, essas relações são marcadas por conflito e antagonismo de concepções, portanto, de disputa política em torno de projetos societários divergentes. Por um lado, um projeto que não necessita da universalização da educação básica, pois propõe a formação de trabalhadores adaptados às necessidades do capital e do mercado. Por outro lado, a defesa de "... uma escola pública, unitária, universal, gratuita, laica e politécnica” (p.1131). Nessa perspectiva, Ciavatta e Ramos(2011, p. 31)também defendem a necessidade de se construir um projeto de educação profissional e tecnológica “... que supere a dualidade entre formação específica e formação geral e desloque o foco de seus objetivos do mercado de trabalho para a formação humana, laboral, cultural e técnico-científica...". Na pesquisa realizada por Prediger (2010), a autora observa que essa tensão entre uma perspectiva de formação mais tecnicista por um lado, e uma formação mais humana por outro, continua presente nos Institutos Federais. Além disso, a autora destaca a dificuldade em lidar com diferentes públicos que a instituição passou a acolher a partir da interiorização dos Institutos Federais, tais como alunos/as do meio rural e do meio urbano, trabalhadores, estudantes com deficiência, entre outros.

Como pensar o papel do psicólogo escolar a partir dessa realidade? Essa é uma das principais questões que atravessam as publicações analisadas. Junto com isto, observamos em alguns trabalhos analisados a dificuldade da comunidade escolar de compreender o papel da psicologia escolar, o que também está presente na literatura sobre a atuação do/a psicólogo/a em contextos escolares (Marinho-Araujo, 2010; Nunes Viana, 2016; Schwede, 2016; Zanella, 2003). 
De acordo com essas autoras, a dificuldade de compreensão do papel da psicologia escolar pode ser vista nas demandas apresentadas aos psicólogos/as, centradas nos estudantes e marcadas pelas expectativas de ajustamento destes às normas e condutas escolares, desconsiderando as relações que produzem e/ou mantêm essas demandas.

Por outro lado, a literatura aponta para a necessidade de romper com práticas psicológicas centradas em apenas um dos polos dos processos de ensinar e aprender, ou seja, o estudante, e a necessidade da construção de novos modelos de intervenção que considerem as múltiplas relações que se estabelecem no processo pedagógico e institucional. $\mathrm{Na}$ maioria dos trabalhos analisados nessa revisão de literatura observamos a influência dessas críticas aos modelos tradicionais de intervenção da psicologia escolar. Por outro lado, alguns trabalhos destacam a necessidade de maior ênfase na problematização dos contextos institucionais, assim como das condições que produzem e perpetuam as demandas escolares no interior das instituições de educação profissional e tecnológica.

A quantidade reduzida de profissionais em instituições escolares no Brasil e a fragilidade na formação do/a psicólogo/a escolar podem ser fatores que contribuem para a dificuldade de consolidação dessa área da psicologia. Marinho-Araújo (2010, pp. 21-22) destaca a diversidade de demandas dos contextos educacionais na contemporaneidade e a necessidade de

... um perfil profissional comprometido com a pesquisa, com um contínuo investimento pessoal e profissional, com escolhas teóricas que atribuam sentido e significado à atuação, com o desenvolvimento de competências e de posturas éticas que oportunizem crítica e lúcida compreensão do sistema educacional em suas dimensões político-sociais.

\section{Considerações Finais}

Evidencia-se, com esta revisão sistemática, a presença de psicólogos/as atuando e produzindo conhecimentos sobre psicologia escolar na rede de educação profissional, científica e tecnológica brasileira. A inserção recente de psicólogos/as nessa rede vem sendo problematizada a partir de variadas publicações, as quais visibilizam, por um lado, os esforços no sentido de construção de atuações consoantes com as complexas características desses contextos e, por outro, os desafios que se apresentam para esses/as profissionais. Ressalta-se o importante crescimento dessas publicações nos últimos anos e sua diversidade geográfica. Porém, a pesquisa sinaliza a necessidade de novos estudos que possibilitem compreender a complexidade dos contextos, as possibilidades de intervenção para psicólogos/as e os desafios a serem superados.

Em relação aos desafios que se apresentam aos/ as psicólogos/as evidenciados nas publicações analisadas, chama a atenção a consonância com debates sobre a formação e atuação do/a psicólogo/a escolar e educacional que vêm sendo desenvolvidos nas últimas décadas, no Brasil. Esses debates apontam as lacunas na atuação. Por certo há e sempre haverá lacunas, posta a dinamicidade dos contextos educacionais e públicos atendidos que inviabilizam a segurança da condução estrita de intervenções previamente programadas. Mas, há também alguns acertos, e importante se faz visibilizá-los para que possam reverberar. Entendemos que os acertos se apresentam como resultado e ao mesmo tempo condição de aberturas para a invenção e construção de possibilidades outras para a atuação de psicólogos/as em contextos educacionais, para estar com os/ as outros/as com os/as quais trabalham e para a reinvenção das relações que ali se estabelecem e das quais ativamente participam.

No que se refere à formação, lacunas também se apresentam. Mas nesse caso também se faz necessário problematizar o que é considerado como ideal a orientar a assunção da falta. Que expectativas repousam sobre processos formativos? Há limites em todo e qualquer processo de formação, ainda mais se considerado como finito e pautado pela expectativa de domínio técnico que prescinde da leitura de contextos e condições de viabilidade da intervenção em parceria com outros/as profissionais, com as próprias pessoas com as quais se trabalha. Entendemos, ao contrário, a formação como processo permanente. Ainda que se apresente como fundamental a discussão, em contextos de formação de psicólogos/as, da história e das especificidades da educação profissional, científica e tecnológica brasileira, faz-se necessário considerar que toda intervenção profissional requer a compreensão da complexidade dos contextos e das relações em jogo, as quais se modificam. Isso demanda a busca constante por atualizações em diferentes campos, necessárias ao diálogo e à construção de possibilidades de trabalho conjuntas com os diferentes atores sociais que ali se encontram.

Talvez o que possa se apresentar como entrave nessa direção seja justamente a busca de uma "identidade" profissional, algo que, por mais que se considere em uma perspectiva de diálogo, se assenta na delimitação de fronteiras, sejam entre áreas de conhecimento, entre áreas na própria psicologia, entre pessoas e os diferentes lugares sociais que ocupam nas instituições de ensino. Perde-se, com a insistência na demarcação de fronteiras ao invés da aposta em sua borrosidade, a possibilidade de se constituírem condições outras para estar em relação e intervir em contextos complexos como o da educação profissional, científica e tecnológica.

\section{Referências}

Andreis, A.; Boaria, P.; Andrade, S. F.; Olea, P. M.; Dias, D. T. Á. (2014). Psicologia escolar: visão dos psicólogos, alunos e docentes do IFRS. Revista Inteligência Competitiva, 4(3), 2342. http://dx.doi.org/10.24883\%2Fric.v4i3.99. Recuperado: 11 fev. 2017. Disponível: www.inteligenciacompetitivarev.com.br/ojs/ index.php/rev/article/view/99. 
Bertollo-Nardi, M. (2014). O trabalho do psicólogo em um campus do IFES: possibilidades e desafios de uma prática. Dissertação de mestrado, UFES, Vitória, ES, Brasil. Recuperado: 11 fev. 2017. Disponível: http://repositorio.ufes.br/handle/10/1588.

Bertollo-Nardi, M.; Bertollo-Nardi, M.; Avellar, L. Z.; Silva, R. D. M.; Trindade, Z. A.; Menandro, M. C. S. (2014). Representações sociais de psicólogo para jovens estudantes. CES Psicología, 7(2), 78-95. DOI 10.21615/2761. Recuperado: 11 fev. 2017. Disponível: http://revistas.ces.edu.co/index.php/psicologia/article/view/2761.

Bisinoto, C.; Marinho-Araujo, C. M. (2015). Psicologia escolar na educação superior: panorama da atuação no Brasil. Arquivos Brasileiros de Psicologia, 67(2), 33-46. Recuperado: 11 fev. 2017. Disponível: http://pepsic.bvsalud.org/pdf/arbp/v67n2/04.pdf.

Bleicher, T.; Oliveira, R. C. N. (2016). Políticas de assistência estudantil em saúde nos institutos e universidades federais. Psicologia Escolar e Educacional, 20(3), 543-549. https://dx.doi. org/10.1590/2175-3539201502031040. Recuperado: $11 \mathrm{fev}$. 2017. Disponível: http://www.scielo.br/pdf/pee/v20n3/2175-3539pee-20-03-00543.pdf.

Bonfante, K. (2014). Barreiras à criatividade pessoal e bem-estar em estudantes do ensino médio e integrado de escolas públicas do Distrito Federal. Dissertação de mestrado, UCB, Brasília, DF, Brasil. Recuperado: 11 fev. 2017. Disponível: https://bdtd.ucb. br:8443/jspui/handle/123456789/1835.

Carlotto, R. C.; Teixeira, M. A. P.; Dias, A. C. G.; Carlotto, R. C.; Teixeira, M. A. P.; Dias, A. C. G. (2015). Adaptação Acadêmica e Coping em Estudantes Universitários. Psico-USF, 20(3), 421-432. Recuperado: 11 fev. 2017. Disponível: http://pepsic.bvsalud.org/ pdf/rbop/v15n2/08.pdf.

Ciavatta, M.; Ramos, M. (2011). Ensino Médio e Educação Profissional no Brasil: Dualidade e fragmentação. Revista Retratos Da Escola, 5, 27-41. http://dx.doi.org/10.22420/rde.v5i8. Recuperado: 11 de fev. 2017. Disponível: http://retratosdaescola.emnuvens.com.br/ rde/article/viewFile/45/42.

Costa, M. O. (2016). Psicologia Escolare Juventudes: entre caminhos e armadilhas. Dissertação de mestrado, UFG, Goiás, GO, Brasil. Recuperado: 11 fev. 2017. Disponível: https://repositorio.bc.ufg.br/ tede/handle/tede/6278.

Costa, M. F. (2013). A inclusão escolar sob a ótica do aluno com surdez: subsidiar reflexões para a psicologia e a educação. Dissertação de mestrado, UNIR, Porto Velho, RO, Brasil. Recuperado: 11 fev. 2017. Disponível: http://ri.unir.br:8080/xmlui/ handle/123456789/1285.

Cristino, A. C. C.; Fiorio, B. D. C.; Oliveira, C. L. B. S.; Felipe, K. D. F.; Santos, R. E. (2016). A contribuição da assistência estudantil para o desenvolvimento biopsicossocial de estudantes do Instituto Federal, campus Limoeiro do Norte. Conexões - Ciência E Tecnologia, 10(1), 9-16. https://doi.org/10.21439/conexoes. v10i1.844. Recuperado: 11 fev. 2017. Disponível: http://conexoes. ifce.edu.br/index.php/conexoes/article/view/844

Feitosa, L. R. C. (2016). Psicologia escolar na educação profissional e tecnológica no Brasil: o caso dos Institutos Federais. In: PérezFuentes, M. C.; Gázquez, J. J., Molero, M. M., Martos, Á.; Simón, M. M.; Barragán, A. B. (Orgs.), Variables Psicológicas y Educativas para la Intervención En El Ámbito Escolar - Volumen II (pp. 37-44). Edita ASUNIVEP. Recuperado: 11 fev. 2017. Disponível: https:// dialnet.unirioja.es/servlet/articulo?codigo $=5858890$.

Feitosa, L. R. C. (2017). Psicologia escolar nos Institutos Federais de Educação, Ciência e Tecnologia: contribuições para a atuação na educação superior. Tese de doutorado, UNB, Brasília, DF, Brasil. Recuperado: 20 mai. 2017. Disponível: http://repositorio.unb.br/ handle/10482/23050.

Feitosa, L. R. C.; Marinho-Araujo, C. M. (2016a). Psicologia Escolar e a Educação Superior no Eixo Brasil-Portugal: o caso dos Institutos Federais e dos Institutos Politécnicos. In: Casanova, J. R.; Bisinoto, C.; Almeida, L.S. (Orgs.), Livro de Atas do IV Seminário Internacional Cognição, Aprendizagem e Desempenho (pp. 187199). Minho/Portugal: CIEd. Recuperado: 11 fev. 2017. Disponível: http://repositorium.sdum.uminho.pt/handle/1822/42516.

Feitosa, L. R. C.; Marinho-Araujo, C. M. (2016b). Psicologia Escolar nos Institutos Federais do Brasil: Articulação entre Formação Acadêmica e Formação Profissional dos Estudantes. In: Casanova, J.R.;Bisinoto, C.; Almeida, L.S. (Orgs.), Livro de Atas do IV Seminário Internacional Cognição, Aprendizagem e Desempenho (pp. 17-29). Minho/Portugal: CIEd. Recuperado: 11 fev. 2017. Disponível: http://repositorium.sdum.uminho.pt/ handle/1822/42516.

Feitosa, L. R. C.; Marinho-Araújo, C. M. (2016c). Psicologia Escolar nos Institutos Federais de Educação, Ciência e Tecnologia: Oportunidades para atuação profissional. In: Viana, M. N.; Francischini, R. (Orgs.), Psicologia Escolar: que fazer é esse? (pp. 188-205). Brasília: CFP. Recuperado: 11 fev. 2017. Disponível: http://site.cfp.org.br/publicacao/psicologia-escolar-que-fazer-eesse/.

Ferro, A. S.; Antunes, A. A. (2015). Plantão psicológico: a construção de um "pro-jeto" sobre as vicissitudes humanas no espaço educacional, narrando a intertextualidade de uma experiência psicológica no IFG. Revista Eixo, 4(1), 76-80. http:// dx.doi.org/10.19123/eixo.v4i1.213. Recuperado: 11 fev. 2017. Disponível: http://revistaeixo.ifb.edu.br/index.php/RevistaEixo/ article/view/213.

Frigotto, G. (2007). A relação da educação profissional e tecnológica com a universalização da educação básica. Educação \& Sociedade, 28(100), 1129-1152. Recuperado: 11 fev. 2017. Disponível: https://doi.org/10.1590/S0101-73302007000300023.

Gomes, R. C. (2014). A constituição do self educacional em adolescentes: a produção dialógica de sentidos acerca da 
participação dos pais na vida acadêmica dos filhos. Dissertação de mestrado, UFBA, Salvador, BA, Brasil. Recuperado: $11 \mathrm{fev}$. 2017. Disponível: https://pospsi.ufba.br/sites/pospsi.ufba.br/files/ ramon_gomes.pdf.

Gomes, R. C.; Padovani, A. S.; Dazzani, M. V. M.; Ristum, M. (2014). Significados construídos por adolescentes acerca do processo de escolarização. Psicologia da Educação, (39), 75-88. Recuperado: 11 fev. 2017. Disponível: http://pepsic.bvsalud.org/pdf/psie/n39/ n39a07.pdf.

Guzzo, R. S. L.; Mezzalira, A. S. C. (2011). 2008 - Ano da educação para os psicólogos - encaminhamentos próximos. In: MarinhoAraujo, C. M.; Guzzo, R. S. L. (Orgs.),Psicologia escolar: identificando e superando barreiras (pp. 11-31). Campinas: Alínea.

Macêdo, J. A.; Souza, E. C. (2009). Adolescência e o limite. HOLOS, 3, 207-217. Recuperado: 11 fev. 2017. Disponível: http://www2. ifrn.edu.br/ojs/index.php/HOLOS/article/view/236/269.

Lei n. 12.711, de 29 de agosto de 2012 (2012). Dispõe sobre o ingresso nas universidades federais e nas instituições federais de ensino técnico de nível médio e dá outras providências. Recuperado: 20 mar. 2017. Disponível: http://www.planalto.gov.br/ ccivil_03/_Ato2011-2014/2012/Lei/L12711.htm.

Marinho-Araujo, C. M. (2010). Psicologia Escolar: pesquisa e intervenção. Em Aberto, 23(83), 17-35. http://dx.doi. org/10.24109/2176-6673.emaberto.23i83.\%25p. Recuperado: 11 fev. 2017. Disponível: http://emaberto.inep.gov.br/index.php/ emaberto/article/view/2249.

Ministério da Educação [MEC] (2017). Portal da Rede Federal de Educação Profissional, Científica e Tecnológica. Expansão da Rede Federal. Recuperado: 04 nov. 2017. Recuperado: 15 fev. 2017. Disponível: http://redefederal.mec.gov.br/expansao-darede-federal.

Morais, A.X. (2010). Adaptação social dos adolescentes do IFPE - Campus Vitória de Santo Antão em regime de internato. Trabalho apresentado noV Encontro de Pesquisa em Educação em Alagoas. Alagoas. Recuperado: 11 fev. 2017. Disponível: http://docplayer.com.br/7725232-Palavras-chave-adolescenteinternato-e-adaptacao-social.html.

Morais, A. X. (2011). Identidade Psicossocial dos Adolescentes do Instituto Federal de Educação, Ciência e Tecnologia de Pernambuco (Campus Vitória de Santo Antão). Dissertação de mestrado, UFRJ, Rio Janeiro, RJ, Brasil. Recuperado: $11 \mathrm{fev}$. 2017. Disponível: http://pepsic.bvsalud.org/pdf/revpsico/v12n1/ a08.pdf.

Morais, A. X.; Benelli, S. J.; Monteiro, R. C. (2013). Identidade Psicossocial dos Adolescentes no Regime de Internato na Educação Agrícola. Revista de Psicologia da UNESP, 12(1), 7489. Recuperado: 11 fev. 2017. Disponível: http://pepsic.bvsalud. org/pdf/revpsico/v12n1/a08.pdf.
Moura, M. R. S. (2015). Não é assim de graça!: lei de cotas e o desafio da diferença. Dissertação de mestrado, UNIR, Porto Velho, RO, Brasil. Disponível: http://ri.unir.br:8080/xmlui/ handle/123456789/1321.

Nunes Viana, M. (2016). Interfaces entre a psicologia e a educação: reflexões sobre a atuação em psicologia escolar. In: Psicologia Escolar: que fazer é esse? (pp. 54-72). Brasília: CFP. Recuperado: 11 fev. 2017. Disponível: http://site.cfp.org.br/publicacao/ psicologia-escolar-que-fazer-e-esse/.

Oliveira, C. B. E. (2011). A atuação da psicologia escolar na educação superior: proposta para os serviços de psicologia. Tese de doutorado, UNB, Brasília, DF, Brasil. Recuperado: 11 fev. 2017. Disponível: http://repositorio.unb.br/handle/10482/8804

Pandita-Pereira, A. (2016). A constituição de motivos para as atividades escolares em jovens estudantes do Ensino Técnico integrado ao Ensino Médio. Tese de Doutorado, USP, São Paulo, SP, Brasil. Recuperado: 11 fev. 2017. Disponível: http://www.teses. usp.br/teses/disponiveis/47/47131/tde-07102016-141023/pt-br. php.

Petracco, M.M. (2010). O Serviço de Psicologia do Instituto Federal Sul-Rio-Grandense - Campus Charqueadas: relato de uma construção. In Experiências profissionais na construção de processos educativos na escola (pp. 105-122). Brasília: CFP. Recuperado: 11 fev. 2017. Disponível: http://site.cfp.org.br/wpcontent/uploads/2010/09/Construcao_de_processos_educativos_ publicacao.pdf.

Petracco, M. M. (2017). Os sentidos da educação na rede federal científica e tecnológica. Tese de doutorado, PUCRS, Porto Alegre, RS, Brasil. Recuperado: 20 mai. 2017. Disponível: http:// repositorio.pucrs.br/dspace/handle/10923/10071.

Prediger, J. (2010). Interfaces da Psicologia com a Educação Profissional, Científica e Tecnológica: quereres e fazeres. Dissertação de mestrado, UFRGS, Porto Alegre, RS, Brasil. Recuperado: 11 fev. 2017. Disponível: https://www.lume.ufrgs.br/ bitstream/handle/10183/77886/000758420.pdf?sequence=1.

Prediger, J.; Silva, R. A. N. (2014). Contribuições à Prática do Psicólogo na Educação Profissional. Psicologia: Ciência e Profissão, 34(4), 931-939. https://dx.doi.org/10.1590/1982370001082012. Recuperado: 11 fev. 2017. Disponível: http://www. scielo.br/pdf/pcp/v34n4/1982-3703-pcp-34-4-0931.pdf.

Rocha, F. H.; Atem, É. (2010). Jovens e formação técnica no IFCE: dilemas contemporâneos no processo de escolha. ETD Educação Temática Digital, 12(0), 64-82. https://doi.org/10.20396/ etd.v12i0.860. Recuperado: 11 fev. 2017. Disponível: https:// periodicos.sbu.unicamp.br/ojs/index.php/etd/article/view/860.

Scacchetti, F. A. P.; Oliveira, K. L.; Moreira, A. E. C.; Scacchetti, F. A. P.; Oliveira, K. L.; Moreira, A. E. C. (2015). Estratégias de Aprendizagem no Ensino Técnico Profissional. Psico-USF, 20(3), 
433-446. https://dx.doi.org/10.1590/1413-82712015200306. Recuperado: 11 fev. 2017. Disponível: http://www.scielo.br/pdf/ pusf/v20n3/2175-3563-pusf-20-03-00433.pdf.

Schwede, G. (2016). A atuação do psicólogo escolar: concepções teóricas, práticas profissionais e desafios. Tese de doutorado, USP, SP, Brasil. Recuperado: 20 mai. 2017. Disponível: http:// www.teses.usp.br/teses/disponiveis/47/47131/tde-19072016104148/pt-br.php.

Silva, D. M.; Sarmento, K. S.; Cunha, R. D. T.; Santana Neto, L. J.; Coutinho, J. N. (2013). (Re)conhecendo os/as alunos/as do Proeja: uma proposta de intervenção transdisciplinar. In: Mendonça, S. R. P.; Souza, C. M. P., Rocha, R. C. (Orgs.), O Proeja no IFRN - Refletindo sobre o fazer pedagógico (pp. 31-44). Natal/RN: Editora do IFRN. Recuperado: 11 fev. 2017. Disponível: http:// portal.ifrn.edu.br/pesquisa/editora/livros-para-download/o-proejano-ifrn-refletindo-sobre-o-fazer-pedagogico.
Silva, R. M. (2015). Só vencem os fortes: a barbárie do trote na educação agrícola. Tese de Doutorado, UFSCar, São Carlos, SP, Brasil. Recuperado: 11 fev. 2017. Disponível: https://repositorio. ufscar.br/handle/ufscar/7109.

Urt, S. (2015). (Semi)formação e relações de trabalho: uma análise das concepções de professores do Instituto Federal de Mato Grosso do Sul sobre a Educação Profissional. Dissertação de mestrado, UFMS, Campo Grande, MS, Brasil. Recuperado: 11 fev. 2017. Disponível: http://repositorio.cbc.ufms.br:8080/jspui/ handle/123456789/2450.

Zanella, A. V. (2003). Psicólogo na escola e as "dificuldades de aprendizagem": algumas estratégias e muitas histórias. In: Psicologia e Educação: multiversos sentidos, olhares e experiências (pp. 19-32). Porto Alegre: Editora da UFRGS.

Recebido em: 13 de junho de 2017 Aprovado: 08 de janeiro de 2018 unrestricted use, distribution and reproduction in any medium, provided the original article is properly cited. 